\title{
Uma Análise do Desenvolvimento dos Estudos de Estratégia no Ramo Imobiliário a partir das Influências mais Recentes dos Stakeholders
}

Ernesto Michelangelo Giglio ${ }^{1}$ Arnaldo Luiz Ryngelblum ${ }^{2}$

\section{Resumo}

O negócio imobiliário é o segundo em importância econômica e social no Brasil, mas não figura como tema relevante de pesquisa acadêmica. Assim, o objetivo do trabalho é avaliar a evolução dos estudos de estratégia no negócio, considerando que existem exemplos de desenvolvimentos empíricos cujas características podem propiciar contribuições teóricas em estratégia. Com base na teoria dos stakeholders foi realizado um trabalho de construção de oito categorias que estruturam o negócio. Em seguida, utilizando uma metodologia de análise de conteúdo, foram analisados 48 artigos apresentados nos congressos EnAnpad nos últimos 13 anos. Os resultados apontam uma tendência de foco nos processos operacionais, deixando de considerar a complexidade da cadeia do negócio, as relações entre os atores e as mudanças do campo organizacional. As contribuições a partir dos resultados consistem em identificar inovações e mudanças de stakeholders desse campo organizacional e sua influência sobre as empresas da rede de negócios do ramo imobiliário, o que leva à proposta de um ponto de partida de desenvolvimento de estratégias e um leque de pesquisas para o tema imobiliário.

Palavras-chave: Estratégia. Stakeholder. Ramo imobiliário.

\section{Introdução}

O objetivo do trabalho é discutir a evolução dos estudos de estratégia direcionados ao ramo imobiliário. Tal como outros exemplos de desenvolvimentos teóricos, a partir de análises empíricas, como no ramo automotivo e

\footnotetext{
${ }^{1}$ Doutor pela Universidade de São Paulo, Instituição à qual está vinculado: Universidade Paulista - UNIP. Endereço: Rua Renato Egidio de Souza Aranha, 736, São Paulo-SP-Brasil. CEP: 05353-050.E-mail: ernesto_giglio@yahoo.com.br.

${ }^{2}$ Doutor pela Fundação Getúlio Vargas, Instituição à qual está vinculado: Universidade Paulista - UNIP. Endereço: Rua Ministro Ferreira Alves, 33, ap. 94 b-Perdizes - São Paulo-SP-Brasil. CEP: 05009-060.E-mail: arnaldory@yahoo.com.

Artigo recebido em: 26/10/2008. Aceito em: 25/09/2009. Membro do Corpo Editorial Científico responsável pelo processo editorial: Rolando Juan Soliz Estrada.
} 
serviços de hotelaria, o ramo imobiliário se transforma e desenvolve novas características que propiciam contribuições em estratégia.

Fenômenos empresariais e produção científica são inter-relacionados, assim, negócios como as vendas pela Internet, ou a mudança de comportamento de consumo das classes emergentes, despertam os interesses dos pesquisadores. Nesse movimento, ao refletirem sobre os fatos, criam-se afirmativas, modelos, instrumentos de pesquisa e ferramentas de gestão para aqueles mesmos fatos, interferindo e reorganizando seus caminhos. Alguns dos exemplos mais conhecidos de contribuições da academia para a construção de teorias de estratégias e consequentes modelos de gestão encontram-se no ramo automotivo, com conceitos de produção integrada e global sourcing (SCAVARDA; HAMACHER, 2001); no ramo hoteleiro, com o conceito de hospitalidade (GIDRA, 2005) e no ramo têxtil, com o conceito de customização (GARCIA et al., 2005). Outros setores economicamente importantes, como o da indústria química, auxiliaram no desenvolvimento dos conceitos de parceria (GULATI, 1998); o setor de educação, com o conceito de EAD - Ensino a Distância (SANTOS; RODRIGUES, 1999). Dessa forma, seria esperado que o setor imobiliário, importante social e economicamente, apresentasse um conjunto desenvolvido e articulado de relações entre a teoria e a prática, a academia e o mercado.

Uma revisão bibliográfica prévia indicou que o ramo imobiliário é pouco investigado nos artigos de revistas e outras manifestações científicas da Administração, tais como congressos e encontros. Quando se levantou a produção do tema nos programas de mestrado e doutorado, verificou-se que a área de Engenharia é a que mais produz material a respeito, predominando os temas operacionais, tais como se encontram em Alencar (1993) e Grilo (2002).

A constatação sobre a pequena presença dos temas da formulação, conteúdo e implantação de estratégias nas publicações científicas merece ser investigada, uma vez que o negócio imobiliário é um setor muito importante no Brasil, tanto do ponto de vista econômico, quanto político e social. Além disso, são inúmeros atores participando dos processos, dentre esses os consumidores, os vários fornecedores, as secretarias do governo ligadas à habitação, os bancos, as imobiliárias, as empresas de comunicação; e outros mais indiretamente, como secretarias de vias públicas, associações de bairros, empresas de assessoria; em uma complexa conjunção de interesses. Essa complexidade, associada às características do negócio, que envolve temas tais como as negociações com a cadeia de fornecedores e as incertezas sobre 
as vendas em função da ordem de grandeza do valor desse tipo de bem, ensejaria discussões tais como estratégias das empresas para lidar com essas questões, por meio de alianças, de negociações com os atores do governo, da formação de redes, processos de definição de produtos, participação dos consumidores, decisões conjuntas sobre políticas habitacionais, dentre outros. Esses temas, no entanto, não foram encontrados no levantamento prévio.

Diante desse hiato entre a importância do negócio imobiliário e a produção científica, colocou-se a tarefa de realizar uma análise dos temas abordados em artigos acadêmicos publicados nos últimos anos, buscando os tópicos de estratégia presentes para, a partir dos dados, propor um referencial teórico/instrumental e uma agenda de pesquisa para a área. A afirmativa orientadora é que o incremento de pesquisas na área imobiliária, analisando suas características específicas, pode trazer conclusões que permitam a emergência de novos conceitos e modelos teóricos na área de estratégia, tal como ocorreu nas pesquisas do ramo automotivo, com modelos de produção e logística; e no ramo hoteleiro, com modelos e conceitos de hospitalidade.

A partir da justificativa e do objetivo apresentados percorreu-se o caminho de realizar uma pesquisa bibliográfica utilizando métodos de busca já consagrados em trabalhos com o mesmo objetivo (DOMBROW; TURNBULL, 2002; LUNARDI; RIOS; MAÇADA, 2005), ou seja, analisar a tendência de temas dos artigos de uma área da Administração e construir inferências sobre os resultados. Assim, analisou-se o conjunto de artigos científicos publicados nos últimos 13 anos (1996 a 2008) sobre o negócio imobiliário, nos congressos EnAnpad, tendo como base teórica os conceitos da estratégia dos stakeholders.

\section{A Estratégia dos Stakeholders como Ponto de Partida}

Os vários atores no ambiente externo às empresas que dão origem às influências sobre elas são chamados de stakeholders. Conforme Freeman (1984), stakeholder é qualquer grupo, indivíduo, ou organização que pode afetar, ou ser afetado pelos processos para atingir os objetivos das empresas.

Essa abordagem reconhece que as exigências sobre as organizações crescem continuamente, o que inclui uma variedade mais ampla de grupos tradicionalmente definidos como stakeholders. Ansoff (1965) classificava os stakeholders como primários e secundários, dependendo de quão próximos 
e necessários eles são no relacionamento com as funções econômicas centrais da empresa. Stakeholders primários são aqueles que têm impacto direto na empresa, como os empregados e os consumidores, enquanto que os secundários são aqueles que não atuam diretamente nas atividades econômicas da empresa, mas podem influenciar, ou serem afetados por suas operações, como o governo, a mídia $e$ instituições financeiras.

Com a velocidade das mudanças tecnológicas e sociais afetando as empresas, a teoria dos stakeholders alcançou maior visibilidade. O poder de cada interessado passou a variar em cada campo de negócios, em cada posição das empresas e no tempo, o que implica em constantes análises do jogo de interesses. O correto conhecimento desses interesses, bem como seu tratamento, por exemplo, buscando sinergias, pode, segundo Bethlem (2001), constituir uma vantagem competitiva significativa. A estruturação desse raciocínio ocorre em quatro estágios: a) identificar as características dos stakeholders; b) identificar os interesses dos stakeholders; c) identificar suas estratégias para influenciar a firma. A partir dessas informações, o raciocínio estratégico consiste em; d) reduzir a dependência desses atores, por meio de ações incrementais de adaptação e reestruturação (FREEMAN, 1984; FROOMAN, 1999). Utilizando esse embasamento teórico foram realizados

os passos da metodologia do trabalho, iniciando com alguns dados do construbusiness.

\section{Características do Construbusiness}

Nesta parte apresentam-se alguns dados do mercado imobiliário, os quais justificam a necessidade das organizações desenvolverem estratégias.

O negócio imobiliário, também chamado de construbusiness, é o planejamento, produção, comercialização e manutenção de imóveis industriais, comerciais e residenciais. Conforme Fogaça (2000), o negócio movimentava nos últimos anos da década de 1990 cerca de $\mathrm{R} \$ 128$ bilhões de reais por ano, empregando 13 milhões de pessoas e realiza investimentos no País na ordem de $\mathrm{R} \$ 113$ bilhões por ano. Sua importância econômica está refletida na participação atual de 10,65\% do PIB (CBIC, 2007). Para atender o mercado, o ramo imobiliário brasileiro é composto de 180 mil corretores e 30 mil imobiliárias cadastradas. O negócio divide-se em três ramos distintos: os imóveis industriais (galpões, depósitos); os comerciais (lojas, shoppings, su- 
permercados e prédios de escritórios) e os residenciais (casas e apartamentos). Os ramos industriais e comerciais contam com a atuação de empresas globais, o que não ocorre no ramo residencial, já que sofre influências de valores culturais regionais, o que dificulta a globalização dos produtos e da comunicação (GIGLIO, 1998).

Trabalhos como os de Meyer (2000), Leonardo (2001), Giglio (2002) e Fávero (2005) têm destacado algumas categorias que caracterizam mais fortemente o negócio imobiliário e evidenciam a presença de stakeholders. Entre essas categorias pode-se citar uma clara divisão dos players nos três ramos referidos da construção; uma grande cadeia de fornecedores de todos os produtos do planejamento, construção e vendas; interesses e interferência do governo por meio de legislação sobre políticas habitacionais; longas negociações com os consumidores; interesses divergentes entre corretores e imobiliárias e velocidade de comercialização.

São fatores que apontam para uma complexa estrutura do negócio $e$ uma instabilidade na dinâmica, o que indica ser desejável um raciocínio estratégico a partir das práticas e características do mercado. As análises de decisões de empresários do negócio imobiliário brasileiro, realizadas por alguns autores, têm mostrado, no entanto, que há algumas décadas utilizam-se os mesmos raciocínios estratégicos, a partir de uma visão das capacidades da empresa em itens como equipe de vendas, bancos de dados e parcerias com fornecedores; desconsiderando as relações com outros atores (PSILLAKIS, 1974; BALARINE, 1998; GIGLIO, 1998; OLIVEIRA, 2000). Já, em alguns artigos internacionais, essas relações com os atores são consideradas nas decisões estratégicas (BOND, 2000; GIBLER, 2002; SWAYER, 2003; ABDUH, SKIBNIEVSKY, 2004; HUGHES, 2004). Essas evidências levantam a questão do hiato existente entre a importância social e econômica do negócio imobiliário, somado à necessidade de desenvolvimento de estratégias em um mercado complexo e, por outro lado, os sinais de baixa contribuição acadêmica para a discussão e desenvolvimento de conceitos de estratégias vinculados às características do negócio.

Uma hipótese que pode ser levantada é a de que a cognição dos executivos dessa área e dos pesquisadores que dela se ocupam, no sentido dado por Child e Smith (1987), que é a capacidade de formar um quadro coerente, não têm se modificado nos últimos anos, enquanto que o negócio se modificou, conforme transparece em fatos como a criação dos planos diretores de desenvolvimento de municípios, a emergência de uma categoria profissional denominada gerente de cidade e a inclusão de inúmeros atores an- 
tes ausentes na aprovação de empreendimentos imobiliários residenciais, tais como Departamento de Trânsito e Secretaria do Meio ambiente.

A partir da discussão desse problema/hiato entre a teoria e a prática, entre o mercado e a academia, surgiu o plano de investigação do artigo.

\section{Metodologia}

Definido o problema de pesquisa como a verificação da evolução dos estudos de estratégia no ramo imobiliário e a análise do hiato entre teoria e prática, mercado e academia; o primeiro passo metodológico foi analisar o material já de posse dos autores, tendo como base a teoria dos stakeholders, a fim de construir as categorias que serviriam de guia para a análise dos artigos dos congressos. Conforme Bardin (1977), quando estamos diante de um fenômeno já conhecido e que conta com certa quantidade de material já publicado é possível organizar os conhecimentos em algumas categorias, as quais servem de guia para as análises posteriores. Assim, utilizou-se um material composto de artigos de revistas científicas e de mercado, teses, pesquisas de mercado, artigos de jornais, entrevistas de executivos em mídias de massa, palestras nas associações de classe e relatos informais dos últimos 20 anos, ou seja, uma coletânea que não há espaço para referenciar todos e que constitui um conhecimento acumulado sobre esse mercado. Para critérios de validade, seguindo os preceitos de triangulação (FLICK, 2004), foram selecionadas as categorias que se repetem nessas várias fontes e indicadas algumas referências bibliográficas de apoio.

\subsection{Clara Divisão dos Players dos Negócios Industriais, Comerciais e Residenciais}

Balarine (1998), Giglio (2002), Rosseto e Rosseto (2002) afirmam que no negócio industrial estão os fornecedores e clientes globais, com poucos concorrentes locais. No negócio comercial encontram-se grandes construtoras, formando um oligopólio, especialmente quando se trata de obras como shoppings, ou algumas obras do governo, como represas e pontes. No negócio residencial encontra-se um amplo leque de empresas, com algumas divisões definidas, tais como aquelas que só atuam em mercados de baixa ren- 
da, ou os especialistas em imóveis de lazer, ou os focados em lançamentos de apartamentos e outras divisões. São raros os movimentos estratégicos destas últimas para entrar em outras áreas do negócio mais lucrativas, prevalecendo certo conformismo das empresas. Existem, no entanto, casos de reposicionamentos, como ocorreu com a construtora Odebrecht, mudando a sua arena competitiva.

\subsection{Longos Processos de Produção}

O período de construção de um imóvel, em qualquer dos ramos de negócio, é de vários anos. Um imóvel residencial que começa a existir na aquisição do terreno estará pronto somente em três anos. Uma construtora que tenha apenas dois empreendimentos em desenvolvimento deveria construir um claro raciocínio estratégico, já que seu futuro estaria dependendo de apenas dois produtos. Considerando só o passo inicial do processo, que é a capacidade de captar terrenos, já se tem uma dimensão estratégica importante. O material utilizado indica que os construtores têm adotado uma posição passiva, esperando as ofertas de terreno. Conforme Balarine (1998) e Giglio (2002), isso demonstra uma baixa valorização desse ator, o proprietário do terreno, e uma falta de visão, uma vez que em todas as cidades grandes as ofertas de terrenos estão diminuindo.

\subsection{Extensa Cadeia de Fornecedores e Diversidade de Variáveis}

Na produção de um imóvel há participação de muitos fornecedores, o que implica em um alto grau de negociação nos relacionamentos e conhecimento dos interesses em jogo. Normalmente, essa rede de empresas é liderada pela chamada incorporadora, que estabelece um triângulo de ligação com a construtora e a imobiliária e comanda as empresas terceiras da construção e comercialização. É essa empresa que também faz as ligações fora da rede, com a prefeitura, os bancos, as secretarias de habitação, saneamento, sistema viário, etc. No desenvolvimento do produto, leva-se em consideração uma grande quantidade de variáveis, algumas das quais transcendem as características do produto e os interesses dos construtores, tais como impacto ambiental, ruído e fluxo de trânsito no local. Apesar das mudanças do campo organizacional, como o estilo de vida das pessoas e as políticas públicas de habitação, os produtos oferecidos continuam com um padrão, com ligei- 
ras mudanças ao longo do tempo (ROSSETO; ROSSETO, 2002; GIGLIO, 2006).

\subsection{Interesses e Interferência Direta do Governo}

Um ponto de incerteza e pressão ambiental origina-se na contínua interferência do governo, que edita leis de financiamento, de proteção ao consumidor, de negociação em bolsa, de uso do fundo de garantia, só para citar alguns; que mudam os cenários e os processos. O negócio imobiliário interessa de perto ao governo, pois empreendimentos tais como um shopping, uma fábrica, ou um conjunto de imóveis de baixa renda, promovem alterações sociais e econômicas nas regiões, o que move as ações dos políticos e dos vários órgãos do governo, como as secretarias da habitação e do trabalho. Apesar da existência desses atores, não há evidências de ações conjuntas entre as empresas e o governo (QUALIDADE-RS, 2007).

\subsection{Longas Negociações e Compromissos com o Consumidor}

Por se tratar de um alto investimento financeiro e, no caso residencial, de investimento emocional, as negociações com os consumidores no processo de compra são longas, dificultando projeções econômicas, tais como velocidade de vendas. Um consumidor de imóvel residencial demora em média seis meses no seu processo de decisão de busca e compra e nesse meio tempo outros atores secundários, como amigos e parentes influenciam suas decisões e negociações com as empresas imobiliárias. Para as empresas, no entanto, seis meses é um prazo longo demais para a definição da viabilidade de um projeto, uma vez que em geral se coloca o prazo de três meses após o início das vendas. Há, portanto, um intervalo de tempo, com risco para as empresas. Essa situação é histórica e não há indícios de mudança da estrutura de vendas no negócio (GIGLIO, 1998; MARIOTTO; PEREIRA-LEITE, 2005).

\subsection{Interesses Diversos que Afetam o Fluxo Financeiro}

Uma incerteza neste setor é a questão do gerenciamento do fluxo de recursos, já que existem sazonalidades nas vendas. Na construção de um 
shopping, por exemplo, podem ocorrer altas entradas no lançamento e baixas entradas no meio da obra, exatamente no ponto em que as saídas serão altas, por causa da fase de acabamento. A falha no gerenciamento desse fluxo é o motivo de algumas construtoras falirem. O problema ocorre porque existem interesses diversos entre os consumidores, que querem comprar ou no lançamento, ou próximo da entrega e os interesses de outros atores, como os fornecedores e os bancos, que exigem garantias de continuidades e constância nos pedidos (COSTA NETO; BRIM JUNIOR; AMORIM, 2003).

\subsection{Predomínio de uma Orientação para Produção e Vendas, Apesar do Conflito de Interesses}

A comercialização de imóveis residenciais na planta segue um ritual semelhante há dez anos, com os plantões de vendas aos finais de semana, o uso de mídia de massa e sinalização no local, os corretores comissionados e comprometidos com a exclusividade de produtos e a convivência com uma imagem negativa da população sobre esses profissionais (GIGLIO, 1998). Pode-se afirmar que as empresas imobiliárias e construtoras atuam em um modelo orientado para a produção e vendas (KOTLER, 2000). As características do negócio, no entanto, indicam que seria possível criar produtos específicos, adaptados a segmentos como idosos e formas específicas de comercialização, por exemplo, alterando as regras de comissões e exclusividades dos corretores, formando uma rede de vendedores. Há um conflito de interesses entre os participantes da ponta da negociação que não tem sido objeto de investigação e solução (GIGLIO, 1998; DANTAS, 2000; UGALDE, 2006).

\subsection{Processos Empíricos para Decisão sobre Novos Produtos}

Balarine (1988) e Giglio (2002) afirmam que não há um raciocínio estratégico sobre os produtos a serem oferecidos pelas empresas. Os empresários decidem com base na intuição, principalmente com um modelo mental de repetição do sucesso do passado. Na prática, ocorrem vários fracassos de lançamentos nas três divisões mencionadas, com prédios de apartamentos, lojas de shopping e boxes industriais que não são vendidos.

A análise do material resultou na convergência de oito categorias, as quais indicam um negócio com incertezas, complexidade e interesses diver- 
gentes em jogo. Por outro lado, mostram que há uma conformidade e repetição de padrões decisórios. Há indícios de imobilismo na busca de arranjos entre os atores, em função de uma tendência em se valorizar os aspectos processuais e gerenciais. As empresas parecem atuar em um modelo orientado para a produção, sem valorizar os interesses de stakeholders envolvidos diretamente. As práticas são as mesmas nos últimos dez anos, ignorando as mudanças no campo organizacional (BALARINE, 1988; ROSSETO; CUNHA, 1999; GIGLIO, 2002).

De acordo com a teoria dos stakeholders, ocorrem mudanças nos interesses dos atores, as quais alteram as formas e conteúdos das relações, exigindo uma adaptação contínua. Quando os interesses mudam o campo, mas os empresários continuam com as mesmas regras, surgem conflitos de interesses, o que, na prática, significa que algumas empresas perdem espaço em sua posição competitiva (KOGUT; SHAN; WALTER, 1992). O material analisado fornece indícios de que o campo organizacional e o comportamento dos atores do negócio imobiliário vêm se transformando, mas as decisões estratégicas e práticas das empresas não, o que mostra a necessidade de um trabalho de adaptação, incluindo a participação de pesquisadores acadêmicos.

\section{O Ramo Imobiliário como Tema Científico}

Após a eleição das oito categorias que configuram um campo complexo de jogo de interesses no ramo imobiliário, colocou-se como segundo passo metodológico analisar o conteúdo dos raciocínios estratégicos nos artigos brasileiros dos últimos anos. Um primeiro levantamento nos sítios de busca da Internet, como o Google acadêmico, Scielo, portais da Capes, CNPq e Anpad, mostrou que há um pequeno número de teses, dissertações e artigos brasileiros oriundos da Administração, quando comparado a outros campos como Direito, Engenharia e Arquitetura. No acervo da biblioteca da Universidade de São Paulo, por exemplo, verifica-se que na Engenharia Civil e na Arquitetura o assunto é pesquisado com regularidade, inclusive com temas relativos à Administração, tais como gerência de produtos e qualidade (ALENCAR, 1993; GRILO, 2002). Os últimos 21 números da Revista de Administração da Universidade de São Paulo - RAUSP, compreendendo o período de janeiro de 2003 a junho de 2008, não apresentam nenhum artigo sobre o negócio imobiliário, o mesmo ocorrendo com os últimos 20 núme- 
ros da Revista de Administração de Empresas da Fundação Getúlio Vargas RAE, compreendendo o período de janeiro de 2003 a março de 2008 . Na edição de abril/junho de 2008 encontra-se um artigo sobre confiança e satisfação do consumidor.

Considerando esse quadro inicial, decidiu-se analisar o conteúdo dos artigos publicados nos últimos anos no congresso EnAnpad, o qual representa a atualidade dos temas científicos brasileiros em Administração. O objetivo da pesquisa é investigar a presença e forma de análise das oito categorias que estruturam o negócio imobiliário, as afirmativas sobre estratégias e as contribuições teóricas e de gestão.

O período de análise da pesquisa foi de 13 anos, de 1996 a 2008. Outros estudos que seguiram o mesmo objetivo de análise de acervo (LUNARDI; RIOS; MAÇADA, 2005; PEGINO, 2005; DEMUNER, 2006) colocam uma década como tempo suficiente para a evidência da tendência de abordagens sobre um tema, ou negócio. Nos 12 congressos buscaram-se os artigos que contivessem as palavras-chave nos títulos, tais como "construbusiness, construção, construtoras, corretores, empreendimento, estratégia, imobiliária, imóveis, negócios imobiliários, planejamento urbano". Selecionados os artigos, realizou-se uma análise de conteúdo (BARDIN, 1977), a partir das categorias já apresentadas. Conforme preceitos desse tipo de análise, são aceitos dois princípios: a) Os artigos analisados apresentam as opções teóricas dos pesquisadores e reapresentam o fenômeno, ou seja, retratam a situação $e$ as decisões das empresas no negócio imobiliário. b) Todo material possibilita três níveis de análises: um primeiro que organiza os dados em torno das categorias eleitas, um segundo que cria inferências de relações entre os dados e um terceiro que cria interpretações e hipóteses dentro de um referencial teórico.

\section{Apresentação e Análise dos Resultados}

Foram analisados 48 artigos apresentados no congresso EnAnpad nos últimos 13 anos, os quais apresentaram uma tendência de análise gerencialista, com foco nos processos produtivos da construção civil.

Em um primeiro arranjo do material, organizaram-se algumas informações, tais como o título, os autores, o ano da publicação; a classificação na 
Anpad $^{3}$ e as palavras-chave do título e do resumo, permitindo uma visão do leque de produção. Os resultados podem ser vistos na Tabela 1. Dos 48 artigos analisados, a área mais investigada é a categoria Organização e Estratégia, com 13 trabalhos, seguida de Operações, Logística e Serviços, com 8 trabalhos. As áreas menos investigadas são Recursos Humanos e Administração da Ciência e Tecnologia, com um artigo cada uma. Chama a atenção o baixo interesse dos pesquisadores por essas áreas, considerando que o construbusiness emprega milhões de pessoas no Brasil, nas mais diversas especialidades e a tecnologia é fator importante na produção.

Os artigos foram elaborados por 83 autores, dos quais 13 apareceram mais de uma vez e três deles escreveram mais de dois artigos. Dos 13 artigos classificados em Organização e Estratégias, sete têm títulos que levariam a raciocínios estratégicos. Algumas categorias, como $\mathrm{RH}$, Empreendedorismo e Tecnologia apareceram uma única vez nos 13 anos. A área de Marketing não apresentou nenhum trabalho durante sete anos (1998 a 2004). A presença de palavras-chave, tais como estratégia, alianças, stakeholder e dependência de recursos; que poderiam indicar uma abordagem estratégica, pois indicam desde o resumo que há uma tendência para processos de qualidade, produção e controles, em uma linha operacional.

Tabela 1: A distribuição dos artigos apresentados no EnAnpad, de 1996 a 2008, conforme a classificação do congresso

\begin{tabular}{|l|c|c|c|c|c|c|c|c|c|c|c|c|c|c|}
\hline & 96 & 97 & 98 & 99 & 00 & 01 & 02 & 03 & 04 & 05 & 06 & 07 & 08 & Soma \\
\hline Organiz e Estratégia & & & 1 & 2 & 1 & 2 & 2 & 2 & 2 & & 1 & & & 13 \\
\hline Operaç. e Logística & & 1 & 2 & 1 & & 1 & & & 1 & 2 & & & & 8 \\
\hline Finanças/Contabilide & & & & & 1 & 1 & & 1 & & 1 & 1 & 1 & 1 & 7 \\
\hline Marketing & 1 & 1 & & & & & & & & 2 & 1 & & & 5 \\
\hline Gestão e divisões & 1 & & & & & & & 1 & 2 & 1 & & & & 5 \\
\hline Adm. da Informação & & & 1 & & 1 & 1 & & & & 1 & & 1 & & 5 \\
\hline Empreendedorismo & & & & & & & & 2 & & & & & & 2 \\
\hline Recursos Humanos & & & & 1 & & & & & & & & & & 1 \\
\hline $\begin{array}{l}\text { Adm. Ciência e } \\
\text { Tecnologia }\end{array}$ & & & & & 1 & & & & & & & & & 1 \\
\hline Ensino e Pesquisa & & & & & & & & & & & & & 1 & 1 \\
\hline Soma & 2 & 2 & 4 & 4 & 4 & 5 & 2 & 6 & 5 & 7 & 3 & 2 & 2 & 48 \\
\hline
\end{tabular}

Fonte: Elaborado pelos autores, a partir de análise bibliográfica (2008)

${ }^{3}$ Como essas categorias mudam com a evolução da Administração, foram realizadas algumas uniões pertinentes, como Gestão, Gestão Ambiental e Gestão Internacional. 
Uma constatação, nessa primeira organização, dos dados é que mesmo na presença de conteúdos referidos pelas categorias, tais como conflitos entre os players e interferências do governo, a tendência é abordar os aspectos operacionais.

Em uma segunda organização dos dados buscou-se verificar a tendência e o leque dos objetivos explicitados nos artigos e seus desdobramentos no corpo do texto. Os dados mostram concentração nos objetivos de conhecer, descrever e analisar fatores que intervêm em um processo, como produção, controles, fluxo financeiro; ou em uma área específica, como gestão do produto, gestão de alianças e políticas públicas. Trata-se, basicamente, de organizar um conjunto de informações, com métodos descritivos, aplicado a vários temas, como consumidores, alianças, direito, tecnologia, logística, produção. As discussões nas conclusões seguem o caminho da constatação e comparação, sem problematizar, criticar ou criar conhecimentos. A divisão da Administração que mais aparece é a de produção, com 16 textos, indicando a vocação operacional dos artigos e do negócio. Apenas dois artigos referem-se a propostas teóricas (SILVA; FISHER; DAVEL, 1999; BRANDSTETTER; HEINECK, 2005). Temas mais atuais, como Gestão e Alianças estratégicas aparecem a partir de 2003.

Alguns artigos que apresentam temas que poderiam desenvolver o raciocínio estratégico voltado para os stakeholders, por exemplo em Rodrigues, Carneiro e Petroni (2004), acabam descrevendo os passos para a produção. A exceção ocorre no artigo de Rosseto e Cunha (1999), que descreve um caso de mudanças de uma empresa a partir da visão dos stakeholders.

Em uma terceira organização dos dados, verificou-se a metodologia utilizada nos artigos, entendendo-se como a definição das modalidades de pesquisa e dos recursos metodológicos. Ordenaram-se os dados em uma classificação entre estudos qualitativos e/ou quantitativos e a divisão entre descritivos, empíricos, ou bibliográficos. Essa organização permite discutir as possibilidades de verificação, generalização e desenvolvimento de hipóteses, o que indica a fertilidade de novos conhecimentos de um campo.

A Tabela 2 mostra os resultados $\mathrm{E}$, dinate dos dados, observa-se o predomínio da abordagem qualitativa e dos recursos descritivos, que são, no sentido de formação de Ciência, os primeiros estágios de abordagem de um fenômeno (MARTINS, 2004). Os pesquisadores não realizam experimentos e não arriscam hipóteses, ficando restritos aos limites descritivos. Os outros níveis, inferência e interpretação, estão ausentes. Basicamente os artigos pre- 
tendem comparar um modelo com um ou vários exemplos, concluindo sobre a adequação da realidade ao modelo, raramente discutindo o modelo. $\mathrm{O}$ esperado seria que diante de um negócio complexo e com incertezas, conforme atestam as categorias, haveria certa quantidade de trabalhos com afirmativas orientadoras a serem discutidas, hipóteses a serem testadas e acompanhamento de decisões e implantações de estratégias considerando os vários atores. Mesmo trabalhos com temas mais complexos, que discutem o desenvolvimento de regiões (LOIOLA; QUINTELHA; CARVALHO, 1999; BARROS; HEINECK; SOUZA, 2005) ficam limitados aos aspectos descritivos. Os trabalhos quantitativos também ficam nos níveis iniciais de análise, com frequências e correlações, com exceção do trabalho de Biderman e Sandromi (2005) que utiliza técnicas mais sofisticadas.

Tabela 2: A distribuição dos tipos de pesquisas encontradas nos artigos publicados na EnAnpad sobre o negócio imobiliário, de 1996 a 2008

\begin{tabular}{|l|c|c|c|c|c|c|c|c|c|c|c|c|c|c|}
\hline & 96 & 97 & 98 & 99 & 00 & 01 & 02 & 03 & 04 & 05 & 06 & 07 & 08 & soma \\
\hline Qualitativa & 1 & 1 & 3 & 2 & 2 & 6 & 1 & 6 & 4 & 6 & 2 & 1 & 1 & 36 \\
\hline Quantitativa & 1 & 1 & 1 & 2 & 2 & 1 & 1 & & 1 & 2 & 1 & 1 & 1 & 15 \\
\hline Descritiva & 2 & 2 & 4 & 3 & 3 & 4 & 2 & 5 & 5 & 6 & 3 & 2 & 2 & 43 \\
\hline Empírica & & & & 1 & 1 & 3 & & & & 2 & & & & 7 \\
\hline Bibliográfica & 1 & & & 2 & & & & 1 & & & 1 & & & 5 \\
\hline
\end{tabular}

Fonte: Elaborada pelos autores, a partir de análise bibliográfica (2008)

Concluindo essa primeira parte da análise, os dados apontam para uma produção afastada da complexidade do negócio, com foco descritivo e confirmatório, que não leva à geração de discussões e novos modelos. Essa situação também dificulta o desenvolvimento de raciocínios estratégicos, já que os pesquisadores valorizam as operações.

\section{Análise da Presença das Categorias e seu Possível Tratamento Estratégico}

Após essa primeira parte da pesquisa realizou-se a análise temática dos textos, pautada pela teoria dos stakeholders, a partir das categorias já explicitadas, buscando em cada uma a presença de raciocínios estratégicos. 
A constatação mais básica é que nenhum artigo propõe uma discussão de estratégia a partir das oito categorias apresentadas. Mesmo quando aparece a palavra Estratégia no título, no resumo, nos objetivos ou nas conclusões, o conteúdo se volta para os aspectos técnicos de produção, controles financeiros e processos de qualidade. Os artigos que tratam da história de uma empresa, por exemplo, o fazem ressaltando as ações e não as decisões, ou os movimentos estratégicos. Os artigos sobre controles, que poderiam discutir estratégias genéricas de custos e diferenciação (PORTER, 1991) não entram por esse caminho. Os artigos sobre produção, que poderiam discutir estratégias de diferenciação e design (MINTZBERG, 1987) não o fazem. Os artigos sobre alianças, que tocam no tema de formato de redes, não tocam nos temas de estratégia de cooperação e interdependência que caracteriza essa área.

As evidências mostram que o conteúdo dos artigos e, segundo princípios de análise de conteúdo, a dinâmica das empresas do ramo imobiliário não estão voltadas para raciocínios estratégicos, o que traz como consequência a ausência de produção de conhecimentos sobre estratégias.

Especificamente sobre as oito categorias de análise, foram encontrados os seguintes resultados:

\subsection{Clara Divisão dos Players dos Negócios Industriais, Comerciais e Residenciais}

Não foram encontrados artigos que tenham explorado movimentos estratégicos das empresas, acordos, parcerias ou coalizões, embora existam notícias no mercado sobre mudanças no ramo (GRINBAUM, 2006). Grandes construtoras que atendiam só ao governo, como a Camargo Correa e a Odebrecht, entraram no mercado comercial e residencial. Construtoras de outros estados, como a Colméia, da Bahia, buscaram um espaço no mercado paulista. Imobiliárias que só tratavam de imóveis de luxo, como a Gomes de Almeida Fernandez, buscam espaço nos imóveis populares com outra marca. Os fatos existem, como já apontava Balarine (1988), mas não são investigados sob a perspectiva de estratégias, confirmando um hiato entre os acontecimentos do mercado e a abordagem dos pesquisadores. 


\subsection{Longos Processos de Produção}

O tema de produção é abordado com uma frequência maior do que outros, conforme se viu na Tabela 1, na linha Operações e Logística (oito trabalhos), porém sem entrar na perspectiva estratégica dos stakeholders, ou seja, na busca de adaptações e soluções de conflitos de interesses. O objetivo mais frequente é determinar formas de melhorias nos processos técnicos.

\subsection{Extensa Cadeia de Fornecedores e Diversidade de Variáveis}

Este tema está ausente, embora pudesse ensejar artigos importantes de gestão estratégica na cadeia e na discussão dos formatos organizacionais em redes. O único texto que trata de alianças (BRASILEIRO NETTO; FREITAS; BARROS NETO, 2003) acabou derivando para as questões de participação e apoio da cúpula às inovações.

\subsection{Interesses e Interferência Direta do Governo}

A influência do governo aparece em alguns artigos, tais como os de Salvador (2001) e Romano, Vasconcellos (2003) que tratam principalmente de desenvolvimento local, mas seu conteúdo não evolui para um raciocínio estratégico de negociação de interesses. O que os artigos afirmam é que o governo interfere com normas que as empresas devem atender.

\subsection{Longas Negociações e Compromissos com o Consumidor}

Esse tema, que poderia gerar estratégias orientadas para o mercado, com negociações entre as empresas, os consumidores e outros públicos, conforme Day (2001), aparece com artigos que buscam esclarecer as percepções do consumidor, ou seus processos de escolha, sem discussão dos temas de estratégias de valor e orientação para o mercado. 


\subsection{Interesses Diversos que Afetam o Fluxo Financeiro}

Esse tema está presente, valorizando-se a discussão de melhoria de processos. Estão ausentes algumas possíveis abordagens na perspectiva estratégica, tais como o ganho competitivo e a busca de alternativas nas negociações entre os atores importantes do fluxo, ou a discussão das possíveis estratégias operacionais, conforme Silva (2005).

\subsection{Predomínio De Uma Orientação Para Produção e Vendas, apesar do Conflito de Interesses}

A tendência é de discussão dos processos, custos e controles, sem derivação para estratégias orientadas para capacidades, ou mercado. Conforme discutido no item sobre construção das categorias, há algum tempo se constata a existência de conflitos de interesses entre os representantes dos fornecedores e os consumidores, o que ensejaria reflexões sobre as estratégias orientadas para o mercado e pelo mercado (DAY, 2001).

\subsection{Ausência de um Raciocínio Estratégico na Gerência de Novos Produtos}

Como consequência dos resultados das categorias anteriores, não se encontrou nenhum artigo que discutisse os processos decisórios e os interesses envolvidos dentro de uma visão estratégica, predominando as descrições sobre processos produtivos e fluxos.

\section{Comentários sobre os Resultados}

A análise de conteúdo dos artigos sobre o negócio imobiliário a partir de oito categorias, com base na teoria dos stakeholders, mostrou a dominância nos processos e fluxos internos, indicando que os autores retratam o negócio com características de um mercado estável, com normas estabelecidas e pouco mutáveis, cujos atores externos (corretores, consumidores, governo, empresas terceiras, associações de bairro, entre outros) têm um papel secundário. Há uma lacuna entre esse quadro obtido nos artigos e a estrutura do 
mercado que emerge nas oito categorias. Aplicando os princípios da teoria dos stakeholders, pode-se interpretar que essa lacuna é um exemplo de miopia sobre as mudanças do campo organizacional. Do lado do negócio propriamente dito, cria-se uma situação de tensão e conflito crescente entre os atores, o que se traduz em problemas, desacordos e fracassos no lançamento de produtos (BALARINE, 1998). Do lado acadêmico, essa miopia se reproduz, na medida em que os pesquisadores utilizam o mesmo mapa perceptivo nos seus trabalhos, valorizando os temas operacionais, até porque provavelmente são esses os dados que acabam sendo disponibilizados. A consequência acadêmica é a de que o negócio imobiliário está pouco presente no congresso EnAnpad, quando comparado a outros negócios como o automotivo, bancário e telecomunicações, cujos artigos geram discussões e propõem modelos.

Essa fraca presença contrasta com a importância econômica e social do construbusiness, em um mundo em que a ocupação urbana e a cooperação tornaram-se mais urgentes (UZZI, 1997; SILVA; PORTO, 2003). Ao se construir um prédio de apartamentos na cidade de São Paulo, por exemplo, devese considerar uma complexidade de fatores, tais como sistema viário, capacidade de eletrificação, impacto no visual e qualidade de vida do bairro, fatores antes desconsiderados, pois existiam muitos terrenos e poucos problemas. Essa complexidade envolve interesses de vários atores, cujas pressões e exigências vêm mudando o campo organizacional.

Considerando que o congresso EnAnpad representa a atualidade dos temas científicos brasileiros, a análise dos artigos publicados mostrou que as empresas decidem a partir de modelos de planejamento financeiro e processos produtivos, com raras referências ao raciocínio estratégico das coalizões, das parcerias e das negociações de interesses, que são mais adaptados às condições de complexidade e quantidade de atores do negócio. $\mathrm{O}$ desenvolvimento de um conjunto de oito categorias importantes do negócio a partir da abordagem dos stakeholders mostrou que a produção acadêmica a respeito do construbusiness considera apenas um pequeno grupo de atores, relegando a plano secundário os demais atores que vêm se tornando importantes.

Existe, portanto, um hiato entre a importância e complexidade do negócio, com seus vários agentes e, por outro lado, as manifestações sobre o negócio; aqui representadas pela produção científica. Não se discutem as interseções entre as práticas de produção das construtoras, as políticas de habitação do governo, os movimentos de qualidade de vida, os interesses dos consumidores, os interesses dos agentes financeiros, as relações entre os 
corretores e outros atores e as políticas econômicas dos bancos de financiamento, só para citar alguns atores mais diretos. Os executivos e os pesquisadores estariam míopes a respeito da fertilidade de pesquisas e propostas de estratégias que podem brotar das oito categorias, uma vez que os ingredientes estão presentes, ou seja, a complexidade, a incerteza e o jogo de interesses.

Entre alguns temas que poderiam emergir desse quadro destacam-se os processos conjuntos para definição de produto; as estratégias de desenvolvimento de mercado a partir da orientação para os consumidores; as práticas de comercialização que integram os interesses das construtoras com as imobiliárias e delas com os corretores; a inclusão das políticas ambientais nas decisões estratégicas; a análise do formato de redes de empresas para ofertas e construções de baixo custo; a integração da Administração com os campos da Sociologia e Antropologia que têm analisado o lugar da moradia e do comércio em suas relações com a produção, consumo e lazer; entre outras. Sobre o tema social, por exemplo, estudos (MOSER, 1999) afirmam que o imóvel é investido de inúmeras representações sociais, que são as imagens e sentidos coletivos, conforme definidos por Moscovici (1988), mais do que se afirma sobre os automóveis, que são mais pesquisados. Os espaços sociais e privativos de uma casa, a vida em grupo nos condomínios, a rede de empresas de um empreendimento, os impactos da construção de um shopping para as rotinas de um bairro, ou de uma cidade do interior são temas que se estendem bem além dos aspectos de produção e são relevantes para a criação de artigos sobre as decisões estratégicas. Entende-se ser possível e relevante que o negócio imobiliário alcance um nível de discussão e pesquisa que vá além dos conteúdos descritivos e operacionais encontrados neste levantamento.

\section{Proposta de um Ponto de Partida Teórico para os Pesquisadores}

A análise do material a partir das oito categorias mostrou ser possível e relevante realizar um salto qualitativo dos processos decisórios das empresas participantes no planejamento, produção e comercialização de imóveis, principalmente os residenciais, na direção de uma maior participação dos atores envolvidos. O conteúdo dos textos aponta para uma lógica de estratégia que valoriza os aspectos financeiros e de produção, o que era a escola dominante 
de estratégia até os anos de 1960 (EISENHARDT; ZBARACKI, 1992). A lógica dominante de estratégia na década de 1980 e 1990, que já colocava a ligação entre as condições do meio e o campo organizacional (BETTIS; PRAHALAD, 1995), não aparece.

Do lado acadêmico, para realizar o avanço das pesquisas no ramo, propõe-se a adoção da teoria dos stakeholders, pois essa abordagem é apropriada para oferecer os recursos de um raciocínio estratégico quando se analisam fenômenos complexos e turbulentos (CHAKRAVARTHY, 1982). Esse referencial teórico é capaz de gerar pesquisas reflexivas e de aplicação, uma vez que, segundo Sender e Fleck (2004), o sucesso de uma empresa depende da qualidade das relações de longo prazo com os stakeholders. Esse ponto de partida é promissor, quando se consideram as características do mercado imobiliário brasileiro, com concorrência acirrada e crescentes pressões de outros atores.

Os pesquisadores poderiam estruturar seus artigos a partir dos processos estabelecidos por essa abordagem, como a tipologia de Frooman (1999), isto é, pesquisar quem são os atores, conhecer a força e os interesses de cada um deles, identificar suas táticas e ações para influenciar a empresa e buscar caminhos de coalizões e soluções desses interesses, para diminuir a influência desses stakeholders, principalmente a partir de coalizões. Recentemente Procopiak, Hoffman e Rosseto (2007) deram um passo nessa direção, realizando um trabalho quantitativo sobre a presença de stakeholders na construção civil em Santa Catarina e também ressaltaram a ausência de artigos sobre estratégias no ramo imobiliário.

Para maior proximidade dos pesquisadores com os executivos da área, considerando que eles utilizam predominantemente processos decisórios empíricos, propõe-se o desenvolvimento de artigos que utilizem complementarmente os conceitos de estratégia como prática (WHITTINGTON, 1996; SILVA, 2005). Dessa forma, evidencia-se o operacional que é valorizado pelos executivos, ao mesmo tempo em que se insere o contexto dos agentes emergentes. Em outras palavras, um importante passo para a evolução em raciocínio estratégico é repensar os fundamentos das decisões e práticas no negócio, começando por incluir os interesses de outros atores. Nesse intercâmbio da academia com a prática, o negócio imobiliário estaria se integrando aos movimentos sociais, econômicos e políticos que estão presentes na questão da moradia, trabalho, urbanização e qualidade de vida. Desse ponto de partida surge uma agenda de pesquisa. 


\section{Uma Agenda de Pesquisa}

Conforme McVea e Freeman (2005), a teoria dos stakeholders propicia quatro grandes linhas de pesquisas: a) o marketing estratégico e suas relações com os atores do mercado; b) as estratégias de diferenciação na participação dos atores no desenvolvimento de produtos;c) a solução de questões éticas e de responsabilidade social nas relações da empresa com o seu ambiente; d) as percepções dos atores sobre suas próprias expectativas $e$ as dos outros. Essas linhas seguem a orientação central do caminho estratégico de se buscar uma situação competitiva lidando com os interesses contrários aos da empresa. As quatro grandes linhas em conjunção com as oito categorias desdobram-se em subtemas, construindo um leque de trabalho científico. Com parcerias de apoio financeiro, ou participando como sujeitos de pesquisas, os executivos podem entrar em contato com novos raciocínios estratégicos, realimentando as pesquisas. Foi o que ocorreu no negócio automotivo, bancário, eletrônico e energético. Para iniciar essa revalorização sugerem-se os seguintes passos:

a) Partir das evidências de que o construbusiness é um fértil campo de pesquisas e de desenvolvimento de modelos sobre estratégias. Cada uma das oito categorias criadas e explicitadas, por si, constitui um campo de investigação de estratégias e de práticas. Tem-se, portanto, oito amplos temas: 1. quem são os stakeholders no ramo imobiliário e o que querem; 2 . a rede na cadeia de produção e o conflito de interesses; 3 . as relações com o governo em estratégias de políticas públicas de habitação; 4 . incertezas e complexidade do negócio e suas relações com as estratégias; 5. estratégias de Marketing e relações com os consumidores; 6. relações entre interesses de atores e resultados; 7. estudos de casos de desenvolvimento e implementação de estratégias; 8 . interesses e desenvolvimento de produtos.

b) Considerando a recomendação dos organizadores de revistas e congressos, sobre a validade da produção científica voltar-se aos problemas brasileiros, os pesquisadores podem aceitar que a questão do espaço de moradia e de trabalho é muito importante para a sociedade brasileira, talvez mais do que outros ramos de negócios 
que frequentam os congressos. Surgindo artigos, discussões e parcerias, cresce o interesse dos empresários e vice-versa.

c) A compreensão do negócio deve incluir a complexidade, com seus vários agentes e interesses. O governo, os consumidores, os bancos, os corretores, as associações de bairros e os sindicatos comerciais são agentes interessados nos empreendimentos residenciais, comerciais e industriais. Essa compreensão faz surgir temas de pesquisas e decisões, tais como os paradigmas mentais dos executivos na definição dos produtos imobiliários; relações de poder na cadeia e inovação de produtos. A teoria dos stakeholders é o caminho teórico adequado para uma mudança de paradigma nas pesquisas e gerência da área, já que trata da análise e solução dos conflitos de interesses.

d) Considerando os longos processos de planejamento, produção e comercialização no negócio e a necessidade de raciocínios estratégicos, seria importante desenvolver estudos e sugestões práticas sobre alianças estratégicas, redes imobiliárias, ocupação imobiliária e gestão ambiental. Esses são temas que podem abrigar os vários interesses dos atores.

e) Abrir a mente para o construbusiness, entendendo que a área abrange muito mais do que a construção civil. As lentas mudanças do produto imobiliário, por exemplo, com a inclusão da suíte e do escritório nos apartamentos e a exclusão da área de serviço e da cozinha, podem ser compreendidas em um espectro mais amplo de novos estilos de vida, que podem determinar novas estratégias das empresas, em respostas adaptativas. Os lugares de moradia e trabalho abarcam várias disciplinas científicas e a interdisciplinaridade seria vantajosa para executivos e acadêmicos. Os lançamentos de edifícios residenciais em São Paulo e Porto Alegre voltados para os idosos, ocorrido nos últimos três anos, seriam exemplos de respostas adaptativas.

f) Por fim, uma pesquisa interessante poderia verificar a imagem que os próprios pesquisadores têm sobre o ramo imobiliário e os atores do negócio e suas possíveis resistências em pesquisar e discutir estratégias na área. 


\section{I | Conclusões}

A importância econômica e social do setor imobiliário cria a expectativa de que o tema seja recorrente nas discussões dos meios acadêmicos. No entanto, observações preliminares indicavam a ausência dessas discussões e contribuições científicas. Assim, determinou-se como objetivo deste trabalho investigar as tendências e o leque de conteúdos dos artigos científicos com foco no ramo imobiliário.

A primeira tarefa, que constitui uma das contribuições deste artigo, foi organizar as características do mercado imobiliário em oito categorias, utilizando os conceitos da teoria dos stakeholders. As categorias são: a) clara divisão dos players dos negócios industriais, comerciais e residenciais; b) longos processos de produção; c) extensa cadeia de fornecedores e diversidade de variáveis; $\mathrm{d}$ ) interesses e interferência direta do governo; e) longas negociações e compromissos com o consumidor; f) interesses diversos que afetam o fluxo financeiro; g) predomínio de uma orientação para produção $e$ vendas, apesar do conflito de interesses; h) ausência de um raciocínio estratégico na gerência de novos produtos.

O quadro construído evidenciou que o negócio apresenta-se com complexidade, no sentido de indeterminação de relações causais estritas; com imprevisibilidade, já que o processo de definição, produção e venda do produto imobiliário é longo (em média nove anos entre o planejamento, aprovação, construção, venda e prazo de garantia) e com intenso jogo de interesses entre diversos atores, já que empreendimentos imobiliários causam impactos de várias ordens na região. Tais características, conforme os preceitos da teoria dos stakeholders, implicam na necessidade das empresas participantes criarem e implantarem estratégias competitivas.

Esperava-se, portanto, encontrar discussões científicas sobre as estratégias das empresas do negócio. A análise de 48 artigos publicados nos últimos 13 anos no Congresso EnAnpad mostrou que o tema de estratégia imobiliária está ausente, predominando os raciocínios operacionais.

Por que isso ocorre? Relativo aos empresários, com os quais se mantem contato há muitos anos, a hipótese é que predomina um esquema mental decisório com racionalidade limitada. Ao invés de analisar a complexidade do campo organizacional e criar respostas adaptativas, os empresários decidem seus produtos conforme o padrão de sucesso anterior, como se as condições se mantivessem inalteradas. Cada produto lançado no mercado, por- 
tanto, está envolto na complexidade já existente do negócio somado aos riscos criados na limitação do processo decisório.

Relativo aos acadêmicos, nossa hipótese é a de que predomina a mesma visão reducionista sobre o mercado imobiliário, provavelmente porque as informações que lhes chegam vêm através desses executivos, com informes na mídia sobre a evolução de vendas, sobre a estabilidade do mercado e sua imunidade a crises; além dos sinais sobre as técnicas de vendas (anúncios e placas) que são as mesmas há décadas. Sem acesso a fontes científicas, porque inexistem; o pesquisador não se sente atraído e motivado para esse campo. Cria-se um círculo vicioso de percepções entre os gerentes e os pesquisadores.

Nossa contribuição é mostrar um caminho de quebra dessa situação. $\mathrm{O}$ início desse caminho consiste em aceitar as evidências de que o construbusiness é um fértil campo de pesquisas e de desenvolvimento de modelos sobre estratégias, como fica claro pelas oito categorias. Além disso, de uma perspectiva ética, os pesquisadores podem considerar a validade de trabalhos sobre o importante problema brasileiro da habitação, talvez mais do que outros ramos de negócios que frequentam os congressos.

Assim, o uso da teoria dos stakeholders, tendo como matriz de temas as oito categorias pode ser um quadro referencial inicial para a revitalização da área para pesquisas sobre estratégias. Questões importantes em Administração, como as alianças estratégias, as redes de negócios e a gestão ambiental teriam espaço no tema imobiliário.

Com esse desenvolvimento seria possível criar uma ponte entre pesquisadores e executivos, auxiliando estes últimos em suas tarefas de raciocínios estratégicos, uma vez que predomina o paradigma empirista e o planejamento financeiro. 


\section{An Analysis of the Development of the Strategies' Studies in Real Estate Business from the Influences Most Recent of the Stakeholders}

\section{Abstract}

The construbusiness industry is the second in economic and social importance in Brazil, due to its production output and job creation, but that it does not count among the themes considered relevant in academic research. This paper's objective is to assess in what measure have real estate business strategy studies evolved since there are cases that can contribute to the theoretical development in strategy. Based on the Stakeholder theory, eight categories were developed which are considered to structure this business. Next, making use of Content analysis, 48 articles presented at the EnAnpad conferences during the last 13 years were examined. There are a managerial tendency, focused on production processes in civil construction, evading the complexities of the business chain, the relationships between actors, and the organizational field changes. The contributions consisted in the identification of innovations and changes of stakeholders in this field, and its influence on the network real estate business, what leads to development of a stakeholders' strategy theory and a research agenda.

Key words: Strategy. Stakeholder. Real estate.

\section{Referências}

ABDUH, M.; SKIBNIEWSKI, M. Electronic networking technologies in construction. Journal of Construction Research, New Jersey, USA, v. 5, n. 1, p. 17-42, 2004.

ALENCAR, C. Tomada de decisões estratégicas no segmento de empreendimentos residenciais: uma sistemática de analise. São Paulo, 1993. 328f. Dissertação (Mestrado). Programa de Pós-Graduação em Administração, Universidade de São Paulo, 1993.

ANSOFF, H. Corporate Strategy: An Analytic Approach to Business Policy for Growth and Expansion. New York: McGraw-Hill, 1965. 
BALARINE, O. Planejamento estratégico na indústria imobiliária: evidencias de mercado. In: ENCONTRO ANUAL DA ASSOCIAÇÃO NACIONAL DOS PROGRAMAS DE PÓS-GRADUAÇÃO EM ADMINISTRAÇÃO-ENANPAD. XII, 1998, Natal. Anais do XII EnAnpad, Natal, p. 1-13, 1988.

BARDIN, L. Análise de Conteúdo. Lisboa: Edições 70, 1977.

BARROS, J. HEINECK, L.; SOUZA, D. A aplicação do princípio da mentalidade enxuta na construção civil: os exemplos de Fortaleza:CE. In: ENCONTRO ANUAL..., 2005, Brasília, Anais do XXIX EnAnpad, Brasília, 2005, p.1-16

BETHLEM, A. Estratégia empresarial: conceitos, processos e administração estratégica. 4. ed. São Paulo: Atlas, 2002.

BETTIS, R.; PRAHALAD, C. The dominant logic: retrospective and extension. Strategic Management Journal, Chicago, USA, v. 16, n. 1, p.5-14, 1995.

BIDERMAN, C.; SANDRONI, P. Avaliação do Impacto das Grandes Intervenções Urbanas nos preços dos Imóveis do Entorno: O Caso da Operação Urbana Consorciada Faria Lima. In: ENCONTRO ANUAL... XXIX, 2005, Brasília, Anais do XXIX EnAnpad, Brasília, 2005, p. 1-16.

BOND, M. et al. Uses of websites for effective real estate marketing. Journal of Real Estate Portfolio Management; apr-jun; v. 6, n. 2; p. 203-210, 2000.

BRANDSTETTER, M.; HEINECK, L. Investigação do comportamento dos clientes do mercado imobiliário: Propostas conceituais e metodológicas. In: ENCONTRO ANUAL..., XXIX, Brasília, Anais do XXIX EnAnpad, Brasília, 2005, p.1-16.

BRASILEIRO NETTO, J.; FREITAS, A.; BARROS NETO, J. Alianças Estratégicas e Inovações Organizacionais na Construção Civil: o Caso INOVACON. In: ENCONTRO ANUAL..., XXVII, Atibaia, Anais do XXVII EnAnpad, Atibaia, 2003, p. 1-14.

CBIC: Câmara Brasileira da Indústria da Construção. Estimativas para 2004 e 2005. Disponível em: <http://www.cbicdados.com.br/ constructnumeros1.asp >. Acesso em: 18 jan. 2007.

CHAKRAVARTHY, B. Adaptation: a promising metaphor for strategic management. Academy of Management Review, v. 7, n. 1, p. 49-135, 1982. 
CHILD, J.; SMITH, C. The context and process of organizational transformation: Cadbury Limited in its Sector. Journal of Management Studies, v. 24, n. 6, nov. p. 565-594, 1987.

COSTA NETO, J.; BRIM JUNIOR, J.; AMORIM, P. Estudo de um modelo para análise prévia de viabilidade econômica financeira de empreendimentos imobiliários em Salvador-BA. Salvador, 2003, 47f. Monografia (Especialização). Programa de Graduação em Administração. Universidade Federal da Bahia, 2003.

DANTAS, M. Composto mercadológico de imóveis residenciais: uma análise do ponto de vista do incorporador e do cliente. Florianópolis, 2000. Dissertação (Mestrado). Programa de Pós-Graduação em Engenharia. Universidade Federal de Santa Catarina, 2000.

DAY, G. A empresa orientada para o mercado: compreender, atrair e manter clientes valiosos. Porto Alegre: Bookman, 2001.

DEMUNER, J.; LORDES, V. Coordenação e Controle nos EnANPADs de 1998 a 2005: em Busca da Pesquisa Positiva. In: ENCONTRO ANUAL..., XXX, Salvador, Anais do XXX EnAnpad, Salvador, ANPAD, 2006, p. 1-11.

DOMBROW, J.; TURNBULL, G. Individuals and Institutions Publishing Research in Real estate-1989-1998. Journal of Real Estate Literature, Califórnia, USA, v. 10, n. 1, p. 45-92, 2002.

EISENHARDT, K.; ZBARACKI, M. Strategic Decision Making. Strategic Management Journal, Massachusetts, USA, v. 13, special issue, p.17-37, 1992.

FÁVERO, L. O mercado imobiliário residencial da região metropolitana de São Paulo: uma aplicação de modelos de comercialização hedônica de regressão e correlação canônica. São Paulo. 2005, 319f. Dissertação (Mestrado). Programa de Pós-Graduação em Administração. Universidade de São Paulo, 2005.

FLICK, U. Uma introdução à pesquisa qualitativa. 2. ed. Porto Alegre: Bookman, 2004.

FOGAÇA, E. Construção civil mostra sinais de recuperação. Jornal O Estado de São Paulo, Caderno Economia, São Paulo, agosto, 14, p. B6, 2000. 
FREEEMAN, R. Strategic management: a stakeholder approach. Boston: Pitman, 1984.

FROOMAN, J. Stakeholder influence strategies. The Academy of Management Review, v. 24, n. 2, p. 191-205, apr., 1999.

GARCIA, R. et al. Esforços inovativos de empresas no Brasil: uma análise das indústrias têxtil-vestuário, calçados, móveis e cerâmica. São Paulo em Perspectiva, v. 19, n. 2, p. 60-70, São Paulo, abr./jun. 2005.

GIBLER, K.; BLACK, R.; MOON, K. Time, place, space, technology and corporate real estate strategy. The Journal of Real Estate Research, Pennsylvania, USA, nov./dec., v. 24, n. 3, p. 235-261, 2002.

GIDRA, G. Reconstruções metodológicas como contribuições para uma disciplina de hospitalidade. São Paulo, 2005, 211f. Dissertação (Mestrado). Programa de Pós-Graduação em Hospitalidade. Universidade Anhembi Morumbi, 2005.

GIGLIO, E. Um Estudo exploratório sobre as representações sociais presentes no processo de decisão de compra de imóvel. São Paulo, 1998, 124f. Dissertação (Mestrado). Programa de Pós-Graduação em Administração. Pontifícia Universidade Católica de São Paulo, 1998.

. Contribuição ao desenvolvimento de um modelo de estratégia orientada para a satisfação do consumidor no ramo imobiliário. São Paulo, 2002, 224f. Tese (Doutorado). Programa de Pós-Graduação em Administração. Universidade de São Paulo, 2002.

As relações com os consumidores no modelo de rede: análise dos conceitos e investigação de seu desenvolvimento no ramo imobiliário. São Paulo, 2006, 24f. Relatório de Pesquisa. Programa de Pós-Graduação em Administração. Universidade Paulista, 2006.

GRILO, L. Gestão do processo de projeto no segmento de construção de edifícios por encomenda. São Paulo, 2002, 370f. Dissertação (Mestrado). Programa de Pós-Graduação em Engenharia. Universidade de São Paulo, 2002.

GRINBAUM, R. Odebrecht investirá US\$10 bilhões. Jornal O Estado de São Paulo, Caderno Economia e Negócios, São Paulo, outubro, 4, 2006. 
GULATI, R. Alliances and networks. Strategic Management Journal, Massachusetts, USA, v. 19, p. 293-317, 1998.

HUGHES, S.; TIPPETT, D.; THOMAS, W. Measuring Project Success in the Construction Industry. Engineering Management Journal, Califórnia, USA, v. 16, n. 3, sept, p. 31-37, 2004.

KOGUT, B.; SHAN, W.; WALKER, G. The Make-or-Cooperate Decision in the Context of an Industry Network. In: NOHRIA, N.; ECLES (Eds.). Networks and Organizations. Boston: Harvard Business School Press, p. 348-365, 1992.

KOTLER, P. Administração de Marketing: a edição do novo milênio. São Paulo: Prentice Hall, 2000.

LEONARDO, R. Redes contratuais no mercado habitacional para consumo. São Paulo, 2001, 244f. Dissertação (Mestrado). Programa de PósGraduação em Direito. Universidade de São Paulo, 2001.

LOIOLA, E.; QUINTELHA, R.; CARVALHO, F. A Competitividade da Indústria Baiana da Construção Civil e a Administração de seus Recursos Humanos. In: ENCONTRO ANUAL..., XXIII, 1999, Foz do Iguaçu. Anais do XXIII EnAnpad, Foz do Iguaçu, 1999, p. 1-15.

LUNARDI, G.; RIOS, L.; MAÇADA, A. Pesquisa em Sistemas de Informação: uma análise a partir dos artigos publicados no EnAnpad e nas principais revistas nacionais de Administração. In: ENCONTRO ANUAL..., XXIX, 2005, Brasília. Anais do XXIX EnAnpad, Brasília, 2005, p.1-15.

MARIOTTO, F; PEREIRA-LEITE, L. O Empreendedor num ambiente turbulento: Estudo de Caso da Construtora Adolpho Lindenberg no Período 1960-1980. In: ENCONTRO DE ESTUDOS EM ESTRATÉGIAS, II, Rio de Janeiro. Anais do II 3 E's, Rio de Janeiro, 2005, p.1-16.

MARTINS, H. Metodologia Qualitativa de Pesquisa. Educação e Pesquisa, São Paulo, v. 30, n. 2, p. 289-300, 2004.

McVEA, J.; FREEMAN, R. A Names-and-Faces Approach to Stakeholder Management. Journal of Management Inquiry, Califórnia, USA, v. 14, n. 1, p.57-69, 2005. 
MEYER, J. Adoção de métodos de análise de mercado imobiliário nas decisões de projeto: estudo de caso dos incorporadores residenciais no bairro de Pinheiros no período 1994-1999. São Paulo, 2000, 278f. Dissertação (Mestrado). Programa de Pós-Graduação em Administração. Universidade de São Paulo, 2000.

MINTZBERG, H. The strategy concept 1: five ps for strategy. California Management Review, Califórnia, USA, fall, v. 30, n. 1, p. 11-24, 1987.

. The strategy concept 2: organizations need strategy. California Management Review, Califórnia, USA, fall, v. 30, n. 1, p. 25-32, 1987a. MOSCOVICI, S. Notes towards a description of social representations. European Journal of Social Psychology, Bersted, United Kingdom, v. 18, p. 211-250, 1988.

MOSER, G. O lugar de moradia é parte da identidade de cada um. Jornal de Psicologia - PSI, São Paulo, ano 17, n. 117, jul./ago. p. 14-15, 1999.

OLIVEIRA, M. A utilidade das informações em folders: $\mathrm{O}$ caso do produto edificações habitacionais novas. In: ENCONTRO ANUAL..., XXIV, Florianópolis. Anais do XXIV EnAnpad, Florianópolis, 2000, p. 1-15.

PEGINO, P. As Bases Filosóficas das Publicações na Área de Estratégia das Organizações nos Encontros Nacionais da Anpad. In: ENCONTRO ANUAL..., XXIX, Brasília. Anais do XXIX EnAnpad, Brasília, 2005, p. 1-13.

PORTER, M. Estratégia Competitiva. Rio de Janeiro: Campus, 7. ed. 1991.

PROCOPIAK, J.; HOFFMAN, E.; ROSSETO, C. As estratégias de influência dos stakeholders nas organizações da indústria da construção civil- Setor de edificações em Balneário Camboriú - SC. In: ENCONTRO DE ESTUDOS EM ESTRATÉGIAS, III, 2007, São Paulo, Anais do III 3 E’s, São Paulo, 2007, p. 1-16.

PSILLAKIS, H. Marketing imobiliário. São Paulo, 1974. Dissertação (Mestrado). Programa de Pós-Graduação em Administração. Fundação Getúlio Vargas, São Paulo, 1974.

QUALIDADE-RS. Setor da construção avalia PAC. Programa Gaúcho da Qualidade e Produtividade. Disponível em: < http:// www.portalqualidade.com/programas/pgqp/noticias/noticias/ NoticiasDetalhe.asp?idNoticia=7184 > . Acesso em: 9 fev. 2007. 
RODRIGUES, I. et al. Integração entre gestão ambiental e gestão de projetos no setor da construção no Brasil: Estudo de Casos. In: ENCONTRO ANUAL..., XXVIII, 2004, Curitiba. Anais do XXVIII EnAnpad, Curitiba, 2004, p. 1-15.

ROMANO, B.; VASCONCELLOS, J. Formação e Estruturação do Campo Organizacional da Construção Civil do Espírito Santo. In: ENCONTRO ANUAL..., XXVII, 2003, Atibaia. Anais do XXVII EnAnpad, Atibaia, 2003, p. 1-17.

ROSSETO, C.; CUNHA, C. A importância dos stakeholders no processo de adaptação estratégica: um estudo de caso na indústria da construção civil. In: ENCONTRO ANUAL..., XVIII, 1999, Foz do Iguaçu. Anais do XXIII EnAnpad. Foz do Iguaçu, 1999, p. 1-13.

ROSSETO, C.; ROSSETO, A. O isomorfismo como balizador da formulação estratégica organizacional: Um estudo multi-caso de empresas familiares do setor de edificações. In ENCONTRO ANUAL..., XXVI, 2002, Salvador. Anais do XXVI EnAnpad, Salvador, 2002, p. 1-15.

SALVADOR, E. A adaptação estratégica na indústria da construção civil: Um estudo de caso no setor de edificações na cidade de Passo Fundo - RS. In: ENCONTRO ANUAL..., XXV, 2001, Campinas. Anais do XXV EnAnpad, Campinas, 2001, p. 1-15.

SANTOS, E.; RODRIGUES, M. Ensino à distância: conceitos, tecnologias, constatações, presunções e recomendações. São Paulo: EPUSP, 1999.

SAWYER, S.; CROWSTON, K.; WIGAND, R. The social embeddedness of transactions: evidences for the residential real estate industry. The Information Society, Massachusetts, USA, v. 19, p. 135-154, 2003.

SCAVARDA, 1.; HAMACHER, S. Evolução da cadeia de suprimentos da indústria automobilística no Brasil. Revista de Administração Contemporânea, São Paulo, v. 5, n. 2, p. 201-219, maio/ago. 2001.

SENDER, G.; FLECK, D. Folga organizacional e gestão de stakeholders: um estudo em bancos brasileiros. In: ENCONTRO ANUAL..., XXVIII, 2004, Curitiba. Anais do XXVIII EnAnpad, Curitiba, 2004, p. 1-16.

SILVA, J.; FISCHER,T.; DAVEL, E. Organizações familiares e tipologias de análise: O caso da Organização Odebrecht. In: ENCONTRO ANUAL..., XXIII, 1999, Foz do Iguaçu. Anais do XXIII EnAnpad. Foz do Iguaçu, ANPAD, 1999, p. 1-15. 
Uma Análise do Desenvolvimento dos Estudos de Estratégia no Ramo Imobiliário a partir das Influências mais Recentes ...

SILVA, R.; PORTO, M. Gestão urbana e gestão das águas: caminhos da integração. Instituto de Estudos Avançados da Universidade de São Paulo, v. 17, n. 47, São Paulo, 2003.

SILVA, R. Revisão e crítica da lógica dominante no pensamento estratégico: uma abordagem pela teoria da agencia. In ENCONTRO DE ESTUDOS EM ESTRATÉGIAS, II. Anais do II 3 E's, Rio de Janeiro, 2005, p. 1-14.

UGALDE, M. As emoções e o processo decisório de compra de imóveis por consumidores da terceira idade. In: ENCONTRO ANUAL..., XXX, 2006, Salvador. Anais do XXX EnAnpad, Salvador, 2006, p. 1-16.

UZZI, B. Social structure and competition in interfirms' networks: The paradox of embeddedness. Administrative Science Quarterly, New York, USA, mar. n. 42 , v. 1, p. 35-67, 1997.

WhitTingtON, R. Strategic as Practice. Long Range Planning, London, United Kingdom, v. 29, n. 5, p. 731-735, 1996.

Revista de Ciências da Administração • v. I2, n. 27, p. 86-II7, maio/ago 2010

II7 